\title{
Ehrenmitgliedschaft der DEGUM für Dieter Nürnberg
}

Lieber Dieter, es ist mir eine Freude und Ehre, hier über Dich und Deine Leistungen für den Ultraschall zu sprechen. Kennengelernt haben wir uns gleich nach der Wende im April 1990 in Trassenheide/Usedom und im Oktober 1990 in Binz/Rügen bei der letzten GUM-Tagung der DDR. Schon damals nahm ich Dich wahr als anpackenden, gut organisierten, innovativen und präzise denkenden Kollegen.

Nach einem 1,0-Abitur in Neuruppin studierte Dieter Nürnberg in Berlin Humanmedizin an der Humboldt-Universität. Seine sonografische Ausbildung fand ab 1992 in Stralsund und in der Charité statt.

1985 erhielt er in seinem Krankenhaus in Neuruppin ein „eigenes“ Toshiba-Gerät. Hier baute er eine Ultraschall-Abteilung auf und wurde 1988 Leiter des AK interdisziplinärer US der GUM. Bereits 33 Jahre hat er sich dem Ultraschall verpflichtet.

Nach der Wende setzte er sich erfolgreich für die Integrierung der DDR-Schaller in die DEGUM und in die KVen ein.

Seine wissenschaftliche Laufbahn kann hier nur angerissen werden - für einen NichtUniversitären ist sein veröffentlichtes Werk respektabel. Er publizierte mehr als 50 Originalarbeiten sowie 152 weitere zitierbare Arbeiten.

2 Bücher tragen seinen Namen, darunter eines zu seinem Lieblingsthema, der interventionellen Sonografie. Des Weiteren schrieb er mehr als 30 Buchbeiträge. Habilitiert hat er sich 1994 mit epidemiologischen Studien zur Prävalenz der Cholezystolithiasis an der Universität Rostock.

Seine Leidenschaft für den US verbindet sich mit einer ausgezeichneten Vernetzung und einem hervorragenden Organisationstalent. Auch hier kann ob der Fülle seiner Aktivitäten nur Wesentliches genannt werden. So war er 1991 die treibende Kraft zur Initiierung und Organisation der BerlinBrandenburgischen Ultraschalltagungen übrigens eine lebendige und bewährte Erfolgsgeschichte, denn gerade in diesem Monat fand die 17. BB in Berlin statt. Er ist Gründer der Usedomer-US-Tage, einer

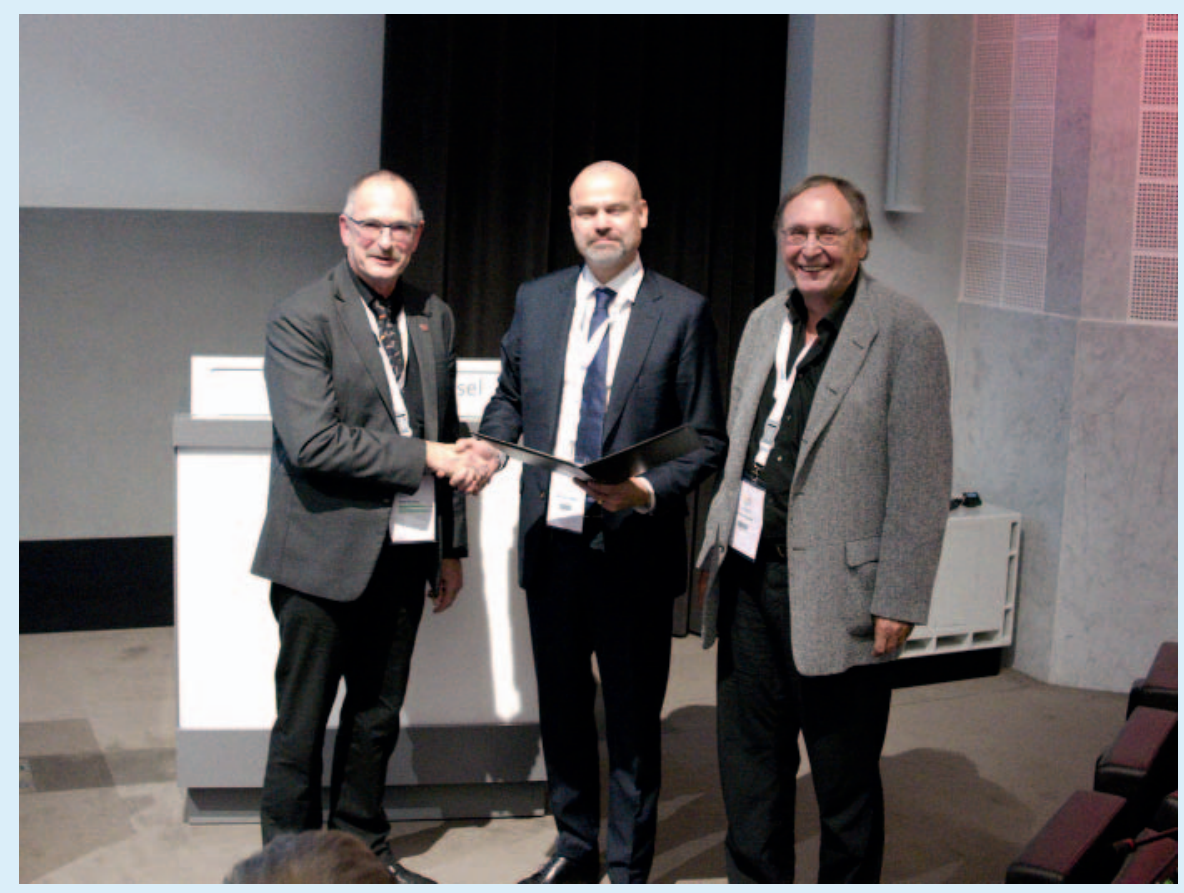

reinen Fortbildungsveranstaltung mit Kursen und Modulen, die regelmäßig über 200 Teilnehmer anzieht.

Sein Engagement für die DEGUM begann nahtlos nach der Vereinigung. 1991 wurde er als Seminarleiter der Sektion Innere Medizin bestätigt. Er leitete als Tagungspräsident das DLT/EUROSON in Berlin 1999. Von 2000 bis 2012 arbeitete er im Vorstand der DEGUM als Schatzmeister und als Präsident.

Als überzeugter Europäer vertrat er die DEGUM 9 Jahre lang als Delegierter beim EFSUMB-Board. Die Aus- und Weiterbildung in US-Learning-Centers wurde zum Schwerpunkt seiner Tätigkeit. Seit 2010 leitet er alle 2 Jahre eine EUROSON-School zur interventionellen Sonografie in Berlin. Im Auftrag der EFSUMB übernahm er 2011 in Nachfolge von Lucas Greiner die Leitung des US-Learning-Centers auf der UEGW.

Sein Wirken geht über Europa hinaus, und als Weltbürger arbeitet er auch für den Weltverband (2013 - 2017 WFUMB secretary \& vice president) und ist momentan zuständig für Beratung und Aufsicht aller Centers of Education weltweit. Besonders am Herzen liegt ihm der Aufbau der USAusbildung im Sudan.
Dieter Nürnbergs Schlagfertigkeit, seine exzellente Rhetorik und Didaktik haben ihn zu einer berufspolitisch engagierten Persönlichkeit werden lassen, aber auch zu einem äußert geschätzten klinischen Lehrer.

Sein bisher bedeutendstes Wirken war die Gründung der Medizinischen Hochschule Brandenburg, deren Gründungsdekan er war. Jetzt leitet er als berufener Universitätsprofessor das Institut für Klinische Ultraschalldiagnostik und erarbeitete ein beispielhaftes US-Curriculum für die Studierenden.

Besonders froh bin ich, dass er noch die Zeit und die Lust hat, die Arbeit in unserem USMuseum zu unterstützen.

Für all diese Aktivitäten braucht man einen langen Atem, und den holt er sich u. a. beim Training für die Marathon-Läufe. Seine beste Zeit waren sagenhafte 2 Stunden und 40 Minuten.

Ja, er ist ein Kämpfer - manchmal unbequem, weil er sein Mäntelchen nie nach dem Wind hängt. Er hat die Gabe, in kritischen Situationen ruhig zu bleiben, Lösungen zu finden und dabei ungemein sympathisch und überzeugend zu sein. Er ist und bleibt ein integrationsstiftender Streiter für den US und wurde deswegen von der Sek- 
tion Innere Medizin als Ehrenmitglied der DEGUM vorgeschlagen.

Vor 1 Monat wurde er für seine umfassenden Tätigkeiten, insbesondere für sein Engagement in der Entwicklung des Hospiz- und
Palliativwesens in Brandenburg, mit dem Bundesverdienstkreuz am Bande geehrt.

Nicht zuletzt wurde er mir über all die Jahre, die wir uns kennen und miteinander arbeiten, ein guter und zuverlässiger Freund.
Lieber Dieter, was ist schon das Bundesverdienstkreuz im Vergleich zur Ehrenmitgliedschaft der DEGUM?

Wir gratulieren Dir dazu herzlich! Bernd Frentzel-Beyme, Berlin 